\title{
MEMÓRIA: TIPOS E MECANISMOS - ACHADOS RECENTES
}

Iván Antonio Izquierdo

Jociane de Carvalho Myskiw

Fernando Benetti

Cristiane Regina Guerino Furini 



\section{MEMÓRIAS E AMNÉSIA}

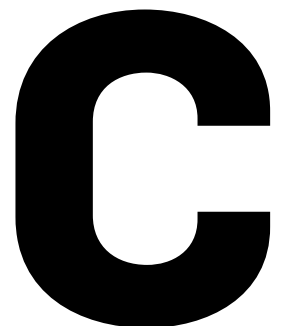

om relação ao conteúdo, as memórias podem ser divididas em dois grandes grupos: as declarativas (eventos, fatos, conhecimentos) e as de procedimentos ou hábitos, que adquirimos e evocamos de maneira mais ou menos automática (andar de bicicleta, usar um teclado). Na memória declarativa participam o hipocampo (uma região cortical filogeneticamente antiga), a amígdala, ambos localizados no lobo temporal, e várias regiões corticais (pré-frontal, entorrinal, parietal, etc.), enquanto, nas memórias de procedimentos ou hábitos, o hipocampo parece estar envolvido apenas nos primeiros momentos após o aprendizado, sendo elas dependentes basicamente de circuitos subcorticais que incluem o núcleo caudato e circuitos cerebelares.

Denomina-se amnésia, em geral, a perda de memória declarativa, pois as doenças que a provocam afetam em maior proporção as áreas vinculadas com esse tipo de memória. A depressão é a causa mais frequente, mas a menos grave. Em geral não se acompanha de dano neuronal irreversível e, ao tratá-la, a amnésia desaparece. As demências (de: partícula privativa; mens: mente) são progressivas e mais graves; envolvem perda definitiva de neurônios e de funções cere- brais. A demência mais comum é a doença de Alzheimer, na qual predomina o déficit de memória. Nela ocorrem lesões nas áreas cerebrais responsáveis pela memória declarativa (córtex entorrinal, hipocampo), e mais tarde em outras partes do cérebro. A doença de Parkinson, nos seus estágios avançados (em que ficam comprometidos circuitos que ligam o núcleo caudato ao córtex), a dependência crônica do álcool, da cocaína e outras drogas, as lesões vasculares do cérebro, o traumatismo craniano repetido (no boxe, por exemplo) e algumas doenças metabólicas (Síndrome de Creutzfeld-Jacob, doença de Pick), também causam quadros demenciais.

\section{AS MEMÓRIAS ESTÃO NAS SINAPSES}

Em fins do século XIX, Santiago Ramón y Cajal, fundador da neurociência, postulou que as memórias obedecem a modificações da estrutura e função das sinapses. Nos últimos trinta anos se demonstrou que isso é verdade, e agora conhecemos as alterações moleculares sinápticas que subjazem à formação, persistência e evocação das memórias em muitas regiões encefálicas.

Denominam-se sinapses as junções entre neurônios, geralmente entre as terminações de seus prolongamentos. Chamam-se axônios os prolongamentos que se dirigem a ou-
IVÁN ANTONIO IZQUIERDO é professor titular de Neurologia da Faculdade de Medicina da PUC-RS coordenador do Centro de Memória do Instituto do Cérebro da PUC-RS e pesquisador principal do Instituto Nacional de Neurociência Translacional do CNPq.

\section{JOCIANE DE}

CARVALHO MYSKIW é professora adjunta de Geriatria e Gerontologia da PUC-RS.

\section{FERNANDO}

BENETTI

é professor adjunto da Faculdade de Medicina do Departamento de Medicina Interna da PUC-RS.

CRISTIANE REGINA GUERINO FURINI

é bolsista pósdoutoral do Instituto Nacional de Neurociência Translacional do CNPq. 
tros neurônios, e dendritos aqueles sobre os quais terminam os axônios. A maioria das sinapses funciona através da liberação de substâncias denominadas neurotransmissores, os quais se ligam a proteínas específicas denominadas de receptores, e sua ativação desencadeia sequências complexas de processos moleculares. Os neurotransmissores podem estimular ou inibir o neurônio seguinte. $\mathrm{O}$ neurotransmissor excitatório mais comum é o glutamato, e o inibitório mais comum é o ácido gama-amino-butírico. Outros neurotransmissores (dopamina, noradrenalina, serotonina e acetilcolina) desempenham em geral funções moduladoras (ver adiante), relacionadas com as emoções, o alerta e o estado de ânimo. Sua liberação está alterada na ansiedade e na depressão.

\section{FUNÇÃO E DURAÇÃO DASS MEMÓRIAS}

Todas as memórias são associativas: se adquirem através da ligação entre um grupo de estímulos (um livro, uma sala de aula) e outro grupo de estímulos (o material lido, aquilo que se aprende; algo que causa prazer ou penúria). O do segundo grupo, que é de maiores consequências biológicas, chama-se estímulo condicionado ou reforço. Em algumas formas de aprendizado, associa-se um grupo de estímulos com a ausência do outro ou de qualquer outro. A forma mais simples dessas formas de "aprendizado negativo" associa um estímulo repetido (um som, uma cena) com a falta de qualquer consequência; esse tipo de aprendizado se chama habituação. Permite que seja possível trabalhar em ambientes cheios de ruídos, ou dormir em ambientes iluminados, por exemplo. Alguns autores consideram a habituação uma memória não associativa.

Do ponto de vista da função, há um tipo de memória que é crucial tanto no momento da aquisição como no momento da evocação de toda e qualquer outra memória, declarativa ou não: a memória de trabalho. Operacionalmente, representa aquilo que a memória RAM representa nos computadores: man- tém a informação "viva" durante segundos ou poucos minutos, enquanto ela está sendo percebida ou processada. Essa forma de memória é sustentada pela atividade elétrica de neurônios do córtex pré-frontal, em rede via córtex entorrinal com o hipocampo e a amígdala, durante a percepção, a aquisição ou a evocação. A memória de trabalho dura segundos e não deixa traços: depende exclusivamente da atividade neuronal on line. Um exemplo é a terceira palavra da frase anterior: durou 2 ou 3 segundos, para dar sentido à frase e conectá-la com a seguinte, mas já desapareceu de nossa memória para sempre. Na esquizofrenia há falhas graves da memória de trabalho, que causam uma percepção distorcida ou alucinatória da realidade.

As memórias que persistem além de segundos denominam-se memória de curta duração e memória de longa duração. A primeira dura 0,5-6 horas e utiliza processos bioquímicos breves no hipocampo e córtex entorrinal, largamente estudados em nosso laboratório. A memória de longa duração perdura muitas horas, dias ou anos. Quando dura anos, denomina-se remota. Sua formação requer uma sequência de passos moleculares que dura de 3 a 6 horas, no hipocampo, nos núcleos amigdalinos, e em outras áreas, durante as quais é suscetível a numerosas influências. A memória de curta duração mantém a cognição funcionando durante as horas que a memória de longa duração leva até adquirir sua forma definitiva. Equivale a "morar num hotel enquanto constroem sua casa".

\section{A CONSTRUÇÃO DA MEMÓRIA DE LONGA DURAÇÃO}

O hipocampo é a estrutura central da formação de memórias declarativas. Integra um circuito que inclui o córtex temporal vizinho (córtex entorrinal), o núcleo da amígdala e áreas corticais distantes. O hipocampo, a amígdala e o córtex recebem também terminações de vias nervosas vinculadas com o afeto, os estados de consciência e o maior ou 


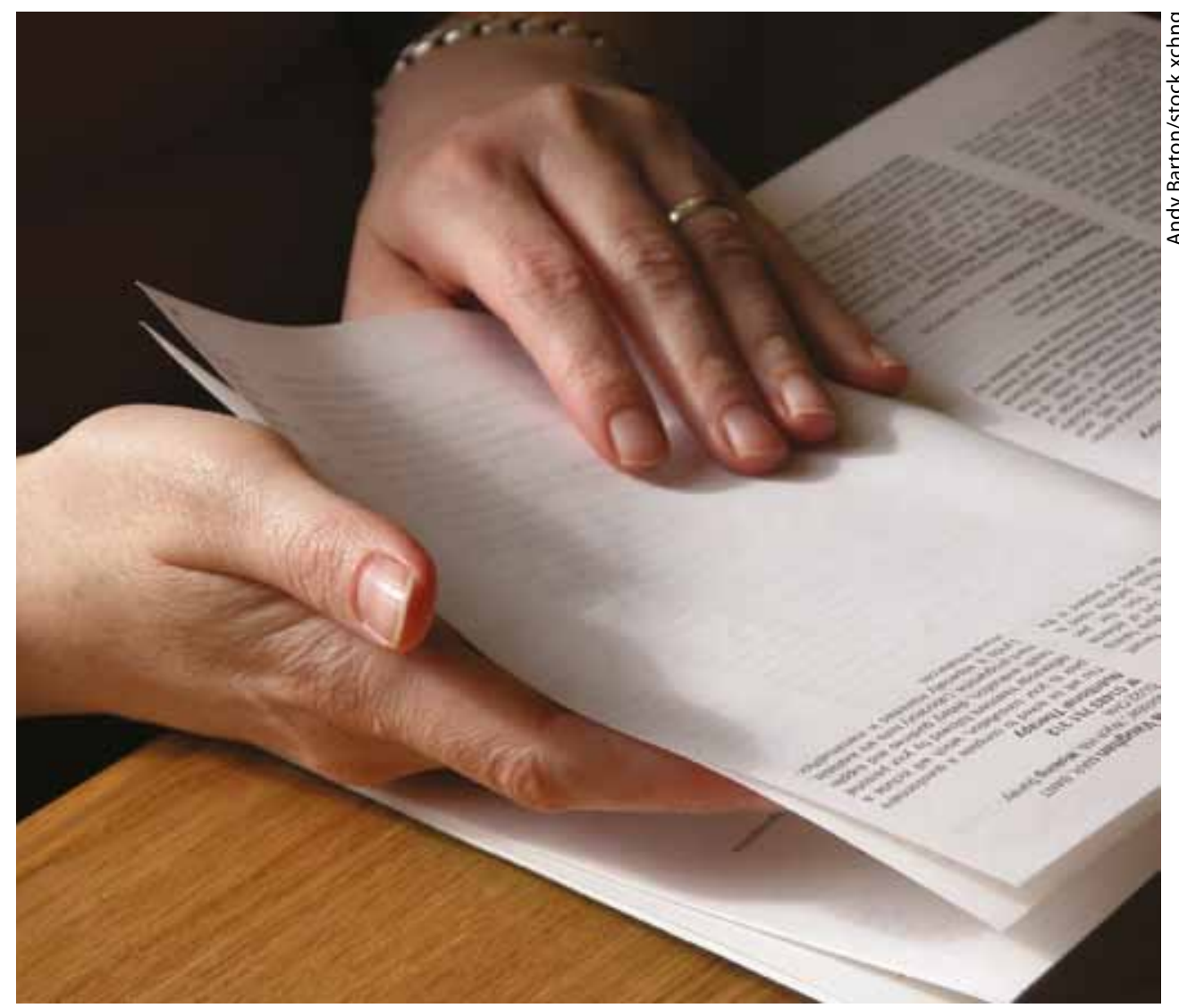

menor grau de alerta, ansiedade ou estresse. Essas vias são: a dopaminérgica, a noradrenérgica, a serotoninérgica e as colinérgicas, que registram e reagem às emoções e estados de ânimo. A dopamina e a noradrenalina são os neurotransmissores da vigília e do alerta. A serotonina regula o estado de ânimo, e falha na depressão. As vias colinérgicas, que usam o neurotransmissor acetilcolina, regulam uma variedade grande de percepções emocionais. Em todos os casos, essas vias agem através de receptores específicos para cada neurotransmissor, localizados no hipocampo, na amígdala e no córtex.

A sequência dos processos bioquímicos no hipocampo necessária para a formação (ou consolidação) de memórias declarativas foi recentemente determinada em detalhe em nosso laboratório. Essa sequência é parecida com a da potenciação de longa duração (em inglês, long-term potentiation - LTP) nessa estrutura, como era de esperar, dado o fato de que ambas consistem em alterações perduráveis da função sináptica ("plastici- dade") na mesma estrutura. A potenciação de longa duração é o aumento de tamanho da resposta de um grupo de neurônios desencadeada pela sua estimulação repetitiva durante alguns segundos, e ocorre no hipocampo durante a consolidação de memórias. Dependendo dos parâmetros de estimulação e/ou do estado prévio de cada sinapse, pode ocorrer, em vez de uma potenciação, uma depressão de longa duração (LTD) da resposta dessa sinapse. Mecanisticamente, a LTP e a LTD são semelhantes: ambas envolvem uma ativação inicial de certo tipo de receptores ao ácido glutâmico, o principal neurotransmissor excitatório; a entrada na célula pós-sináptica de cálcio, seguida da ativação de várias enzimas dependentes desse íon, que permitem a transferência de íons fosfato de umas proteínas a outras e a subsequente ativação da transcrição do DNA, leva à síntese proteica nos ribossomos do citoplasma do neurônio ativado. Há um sistema alternativo de síntese proteica nos neurônios, fora dos ribossomos, independente do núcleo, sensí-

\section{Livro e aprendizado: estímulos da memória associativa}


vel a uma substância chamada rapamicina. Esse segundo sistema de síntese proteica é necessário tanto para a gênese de LTP como para a de LTD (Myskiw et al., 2013).

A sequência dos processos moleculares subjacentes à formação de memórias no hipocampo envolve a ativação de numerosas enzimas que regulam a atividade de proteínas preexistentes, e a produção por elas de ativação gênica e síntese proteica. Muitas das proteínas sintetizadas no hipocampo na formação de memórias se incorporam às sinapses das células hipocampais com as de outras regiões e alteram sua função. Outras regulam esses processos.

Uma das principais proteínas reguladoras das sinapses é o fator neurotrófico derivado do cérebro (BDNF), que atua tanto durante a formação de memórias, como também várias horas mais tarde, quando, liberado no hipocampo por estímulos dopaminérgicos, determina se as memórias que foram consolidadas antes persistirão durante poucos dias ou durante semanas. Paralelamente, atuam também sobre o hipocampo vias noradrenérgicas mediadas por receptores beta, e terminações colinérgicas nicotínicas; a função desses dois grupos de fibras sobre o BDNF não é conhecida. A persistência das memórias procedurais é muito grande (décadas); a das memórias declarativas é muito menor e declina depois dos 40 anos de idade; isso explica por que a partir dessa idade tendemos a recordar menos as coisas mais recentes. O mecanismo não tem relação com o sono e funciona igualmente de dia e de noite. Porém, a falta de sono reduz a persistência das memórias declarativas. Alguns acreditam que isso ocorre porque elas não são ensaiadas (rehearsed), o que é considerado por muitos como necessário para a persistência. Um dos muitos mecanismos propostos para a persistência envolve a reiteração cíclica da ativação da enzima cálcio-calmodulina quinase II, e da elevação simultânea dos níveis de cAMP (sigla do inglês: cyclic adenosine monophosphate) no hipocampo, após a consolidação. De fato, a ativação dessa enzima no hipocampo é necessária para a manutenção das memórias (Silva et al., 2013).

O processo de formação das memórias de longa duração, portanto, é lento e frágil: consiste de muitas etapas, e qualquer uma delas pode falhar. Além disso, várias dessas etapas estão sujeitas a poderosos mecanismos de modulação, através de dois grandes conjuntos de fibras nervosas:

a) vias procedentes da amígdala e do núcleo medial do septuo que, através de axônios colinérgicos e glutamatérgicos, modulam intensamente a formação de memórias no hipocampo. Essas vias estão vinculadas com o conteúdo emocional das experiências que deixam memórias; quanto maior a emoção, maior sua ativação;

b) vias nervosas vinculadas com o afeto, as emoções e os estados de ânimo (dopaminérgicas, noradrenérgicas e serotoninérgicas), procedentes de estruturas subcorticais e estimuladas pela aquisição de uma experiência nova ou a recordação de uma experiência antiga. Essas vias regulam enzimas que afetam o metabolismo da célula nervosa e prejudicam sua capacidade de ativar genes e sintetizar proteínas e, portanto, gravar memórias. Essas vias agem quase ao mesmo tempo sobre o hipocampo, o córtex entorrinal e o córtex parietal. Sua excitação ou inibição é importante para determinar se cada memória de longa duração será efetivamente formada ou não. Uma estimulação intensa da via serotoninérgica ou uma inibição das vias dopaminérgica ou noradrenérgica, por exemplo, podem efetivamente cancelar a formação definitiva de uma memória horas depois de ter sido adquirida.

\section{A MEMÓRIA DE CURTA DURAÇÃOO}

Durante um século houve dúvidas acerca de se os sistemas de memória de curta duração, que mantêm a função mnemônica funcionante enquanto o hipocampo e suas conexões vão tecendo lentamente a trama 
de cada memória de longa duração, são independentes deste último processo ou tão somente uma etapa do mesmo. Em suma: se as memórias de curta e de longa duração são etapas de um mesmo fenômeno ou são, pelo contrário, eventos paralelos, embora vinculados.

Descobrimos, entre 1998 e 2001, que o processamento de memória de curta duração é paralelo ao das memórias de longa duração, e ocorre também no hipocampo e córtex entorrinal.

Esse achado tem implicações clínicas importantes. Na velhice, em muitos casos de demência, no delirium, em alguns quadros de tumores ou lesões do lobo temporal e em vários casos de depressão, há falhas seletivas de um ou outro tipo de memória, principalmente da de curta duração: o paciente não lembra como chegou ao consultório, mas sim fatos ou eventos do dia anterior ou de horas atrás.

\section{A EVOCACÃO DAS MEMÓRIAS}

As principais áreas envolvidas na evocação de memórias declarativas e de procedimentos são basicamente as mesmas utilizadas para sua formação; só que, no caso das memórias declarativas, com o passar do tempo, o hipocampo e a amígdala passam a ter um papel menos importante na evocação, e várias outras regiões do córtex predominam. Na evocação, essas estruturas participam de maneira orquestrada. A evocação é fortemente modulada em todas elas pela dopamina, noradrenalina e acetilcolina, e inibida pela serotonina. É inibida também por corticoides procedentes da suprarrenal, que, como se sabe, são liberados em situações de estresse. Os corticoides explicam os famosos "brancos" na hora da evocação; tipicamente num exame ou numa apresentação em público.

A evocação das memórias declarativas e dos hábitos é tão sensível à modulação por fatores emocionais, ansiedade, ou estresse como sua formação.

\section{A EXTINCÃ̃o DE MEMÓRIAS}

A repetição de uma memória sem o "reforço" (estímulo incondicionado, recompensa, castigo, consequências) leva a sua extinção. Esta constitui um novo processo de aprendizagem, em que uma nova memória - estímulo(s) sem consequência - substitui gradativamente a original - estímulo(s) com consequência. Essa nova memória requer também expressão gênica e síntese proteica no hipocampo e na amígdala. Os mecanismos da extinção são semelhantes aos da formação de memórias, mas, em vez de resultar num aumento das respostas aprendidas, resultam numa diminuição da probabilidade de sua expressão. Na extinção, o que se extingue não é a memória em si, senão a probabilidade de sua evocação (Myskiw et al., 2013).

A extinção tem uma aplicação terapêutica importante no tratamento das fobias e do transtorno do estresse pós-traumático, para o qual é o tratamento de escolha. Esse transtorno é uma das entidades psiquiátricas mais terríveis; nele, o paciente não consegue parar de evocar um episódio traumático e passa a evocá-lo fora de contexto e a qualquer hora, infernizando sua vida. O típico exemplo é o do indivíduo que não consegue mais dormir porque, cada vez que fecha os olhos ou chega a noite, passa a se lembrar da vez em que foi assaltado com violência, ou do choque dos aviões contra as torres gêmeas, ou de algum outro acontecimento muito traumático de sua vida. Na aplicação à psicoterapia, a extinção se denomina "terapia de exposição", justamente porque o tratamento envolve primariamente a repetição de estímulos pertinentes às memórias traumáticas (fotos dos aviões batendo nas torres, figuras de uma pessoa com uma arma na mão, etc.), mas sem o trauma (sem as batidas dos aviões, sem o assalto). Tem uma semelhança com a habituação no sentido em que ocorre perante a repetição de um estímulo sem reforço, só que, à diferença da habituação, se trata de um estímulo que já foi reforçado por sua associação com outro, e da inibição da expressão da resposta 
devida a essa associação (Pavlov, 1959).

A extinção é simplesmente mais uma forma de aprendizado, ou seja, de fazer memórias. Muitos pensam que se deve à LTD mais que à LTP de sinapses hipocampais. A interpolação de uma experiência nova, que desencadeia uma potenciação de longa duração no hipocampo durante a extinção de uma memória traumática, também se acompanha de uma LTP ou LTD no hipocampo. A modificação de um aprendizado resultante de uma LTP ou LTD hipocampal por outro aprendizado resultante de outra LTP ou LTD também hipocampal é a consequência da produção de novas proteínas perto da sinapse que primeiro foi estimulada; outras proteínas, sintetizadas perto de outra sinapse na mesma célula hipocampal, migram à sinapse anterior e "capturam" as proteínas sintetizadas nela. Esse processo denomina-se "marcação sináptica" (synaptic tagging), descoberto por Frey e Morris em 1997, e explica as interações entre memórias próximas no tempo, uma mais forte que a outra e ambas dependentes de LTP ou LTD (Myskiw et al., 2013).

\section{NA SALA DE AULA, NA VIDA DIÁRIA}

1) O melhor exercício para manter a memória é a leitura. Ao ler, o cérebro faz um rápido e enorme scanning de tudo o que tem guardado nele e começa com a letra do abecedário com que se inicia a leitura (a: abelha, alma, avô, etc.; b: barbaridade, burro, beijo, etc.; c: casa, corpo, cabelo, etc., e assim por diante), e depois com cada letra sucessiva. Ao fazê-lo, põe em funcionamento a memória visual, verbal e até de imagens: lembra fugazmente do aspecto das abelhas, avós, burros, casas, etc. Nenhuma outra atividade cerebral tem essa capacidade nesse grau. Por isso é o exercício de escolha para a memória, que é o maior exemplo de que "a função faz o órgão". 2) Permitir ao cérebro que descanse um tempo adequado cada dia, dormindo de preferência nas horas apropriadas.

3) Manter "viva" a memória de trabalho e a memória de curta duração, através da conversa, da leitura, de filmes, etc. Sem elas, será difícil ter uma boa base para formar memórias de longa duração, e não há base para o diálogo e a compreensão de eventos rápidos.

4) Todas as drogas de abuso, a começar pelo álcool, são, em qualquer dose ou em qualquer padrão de consumo (diário, esporádico, muito intenso, pouco intenso), prejudiciais para a memória em suas diversas formas e fases. Já que este é o caso, é evidentemente melhor se abster delas por completo que utilizá-las muito ou pouco.

\section{BIBLIOGRAFIA}

BERMÚDEZ RATTONI, F.; PRADO ALCALÁ, R. A. Memoria: Donde Reside y Como se Forma. México, Trillas, 2001.

FREY, J. U.; Morris, R. G. "Synaptic Tagging and Long-term Potentiation", in Nature, 385, 1997, pp. 533-6.

IZQUIERDO, I. Memória. 2ª ed. Porto Alegre, ArtMed, 2011.

MYSKIW, J. C.; BENETTI, F.; IZQUIERDO, I. "Behavioral Tagging of Extinction Learning”, in

Proceedings of the National Academy of Sciences. USA, 110, 2013, pp. 1.071-6.

PAVLOV, I. P. Conditioned Reflexes. New York, Dover, 1959.

SILVA, W. C. da; CARDOSO, G.; BONINI, F.; BENETTI, F.; IZQUIERDO, I. “Memory

Reconsolidation and its Maintenance Depend on L-Voltage-dependent Calcium

Channels CaMKII Functions Regulating Protein Turnover in the Hippocampus", in

Proceedings of the National Academy of Sciences. USA, 110, 2013, pp. 6.566-70.

SQUIRE, L. R.; KANDEL, E. R. Memória. Porto Alegre, ArtMed, 2002. 